\title{
Optimal Integration of Distributed Generation in Primary Distribution System and its Economics
}

\author{
Vani Bhargava, S K Sinha, M P Dave
}

\begin{abstract}
The paper analyses four types of DG (distributed generators) for their optimal placement in primary distribution system. They are sited and sized optimally to obtain maximum loss reduction. The ultimate objective of the adopted work in this paper is to identify the size and location of distributed generators for their placement in primary distribution network and to justify the economics of these placements. To serve the purpose, an analytical method is used in this paper for determination of sizes and sites for four DG types. The analytical method is considered suitable for the analysis purpose in proposed work. The paper presented a comprehensive analysis for four types of DGs for their placement in primary distribution system. The type $1 \mathrm{DG}$ is capable of delivering real power only whereas type $3 D G$ is capable of providing real as well as reactive power to the distribution network. Out of other two types, type 2 can deliver only the reactive power whereas type 4 supplies active power but at the same time it consumes reactive power. The paper compares the economic feasibility of placement of four DG types in primary distribution system.
\end{abstract}

Index Terms: Distributed Generation, Distribution System,Economics, Optimal Placement

\section{INTRODUCTION}

In recent years, electricity market liberalization, constraints on erecting new transmission lines, carbon footprint reduction requirement due to environmental concerns, reduction of fossil fuel generation and motivating renewable energy generation, caused an increased penetration of distributed resources in distribution system [1].

Generating plant connected to the distribution system directly is termed as the distributed generation or dispersed generation [2]. The dispersed generation can supply consumer load directly as it is connected at the consumer's end. Distributed/dispersed generation improves the quality and reliability of power distribution network. As generation is placed nearer to its utilization point, line losses as well as line voltage drop are also reduced.

It is observed that about $75 \%$ of total system losses take place in distribution system. The reason of higher system losses in distribution system is lack of adequate investments in the same. Also the distribution system is overloaded and has insufficient reactive power support. And the distribution network contains almost $90 \%$ of total system length [3].

A distribution feeder is the part of distribution system tailored to supply the load locations and needs. There are three types of feeder systems: radial, loop feeder and ring

Revised Manuscript Received on July 02, 2019.

Vani Bhargava, Electrical and Electronics Engineering, AMITY University, Noida, Uttar Pradesh, India

S K Sinha, Electrical and Electronics Engineering, AMITY University, Noida, Uttar Pradesh, India

M P Dave, Electrical and Electronics Engineering, Shiv Nadar University, Greater Noida, Uttar Pradesh, India feeder network. Radial feeders have lowest cost and they are easy to analyze although reliability of this system is low. Feeders can be constructed and operated to form a loop and they can be tapped to supply the consumers. There is a point in the loop where power flow is zero. Feeder network is made up of a group of interconnected feeders so connected that there is always more than single root between two points in the network. Loop feeders are designed with to accommodate sufficient capacity protection throughout the feeder length. The reliability provided to consumer by this system is very high but the cost of the system is also high [3].

Worldwide, more than $80 \%$ of electricity distribution is accomplished by the radial distributors having only one path between any consumer and substation. The effectiveness of the distribution system in fulfilling its function is measured by means of voltage regulation, reliability and upon cost.

To mitigate some of the problems associated with the distribution system, distributed generation could be considered as the most viable one and in addition to the same it can meet the ever-increasing electricity demand on the system.

The distributed generation involves smaller sized generators than the central power generating facilities [4].

A large number of definitions are given for distributed generation. Because of large variation in definitions it is better to consider some factors while defining DG. These factors may include purpose of connecting DG, its location, their ratings, the area in which power is delivered, the technology employed, its impact on environment, mode of their operation, ownership of DG plant, its penetration in the system etc. In terms of ratings or size of DG, various agencies define them in a variety of ways. For example EPRI (Electric Power Research Institute) defined DG as a source of generation extending from a few $\mathrm{kW}$ to $50 \mathrm{MW}$. As per GPI (Gas Research Institute) it is the generation between $25 \mathrm{~kW}$ to $25 \mathrm{MW}$ capacity. Preston and Rastler defines the same as generation that ranges from few $\mathrm{kW}$ to $100 \mathrm{MW}$. As per another author Cardell, it is defined as the capacity that ranges between $500 \mathrm{~kW}$ upto $1 \mathrm{MW}$ [5]. CIGRE gives its range as capacities smaller than 50-100 MW.

The paper has taken DG capacity and its location as the factors for optimization of DG placement cost. After defining DG based upon their power rating, let it be defined based upon the location. So based upon this criterion the DG is defined by some authors as a source of power connected to the distribution system network. Some authors define it as the source connected directly to the customer end and some include it even in the transmission system. But it is basically the local generation connected to the distribution network. So it can precisely be defined as the electric

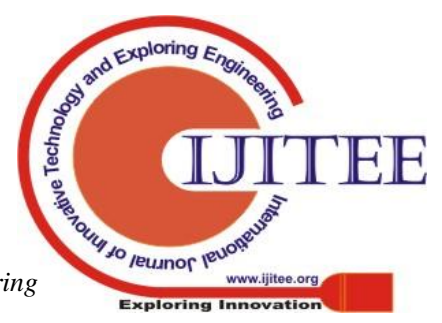


power generation units installed and operated directly in the distribution system which is the customer's side of electric power system.

These generators are distributed throughout the power system but in vicinity to the load. If defined loosely, they are the electricity generators involved in small scale electricity generation. They seem to be comparatively new technology, but the concept as applied to present system is only new. The earliest power stations were actually the generators to supply local load. They were connected to the system where load was also connected. After technology evolution, the concept of transmission grid came in and the generators later on became the central power generating facilities. Then it became possible to transmit the electricity over long distances. The generating facilities were placed near the resource site, electricity generation started in bulk and all this resulted in a reduction in per unit electricity price.

From last decade or so, a renewed interest, resulted from the newer version of electricity market and its changing regulations and economics, in small scale electricity generation or the distributed generation is evolved [6].

The performance of distribution lines is determined by line efficiency and line voltage regulation. The efficiency of line can be determined as

Power delivered at receiving end / (Power delivered at receiving end +line losses)

In the similar way voltage regulation is defined as change in receiving end voltage, expressed as a percentage of full load voltage, from no load value to full load value while sending end voltage is kept unchanged. About $75 \%$ of total losses occur along the distribution system. A reduction in distribution system loss can result in energy saving in a substantial amount and at the same time it will cause an increment in system power capacity, resulting from reduced system losses. Various ways for reducing system losses are :

1. Optimization of line capacity,

a. selecting appropriate $\mathrm{kVA}-\mathrm{km}$

b. selecting appropriate MW-km capacity

2. Optimizing transformer capacity location and use

The losses in distribution system can also be reduced by optimal placement of distributed generators [7]. Optimal placement of distributed generators in system acts as active and reactive power compensation in the system and relieves the substation capacity. As DGs are local generators in distribution system the length of power flow reduces causing an improvement in system voltage profile and a reduction in losses [20],[21],[22].

\section{DISTRIBUTION SYSTEM AND DISTRIBUTED GENERATION}

The number of electricity units generated is not same as the number of electricity units utilized. A percentage of these units are lost in the system connecting generation with the consumer, i.e. in transmission and distribution networks. The amount of units lost in the system is not paid by the consumers. Total percentage of T\& D losses in the system is given as $=[$ Feeder input energy $(\mathrm{kWh})-$ Energy billed at consumer's end (kWh) ]*100 / Feeder input energy (kWh)

Total T\& D losses are categories as:

a. Technical losses

b. Commercial or non-technical losses
Technically losses amount to $22.5 \%$ and out of these losses the main contributors are the primary and secondary distribution system. Transmission and sub-transmission system contribute to approximately $30 \%$ of total technical loss.

Technical losses are further divided into two categories of fixed and variable losses. Fixed losses do not vary with current. They typically amount between $1 / 3$ to $1 / 4$ of the losses.

They are due to corona losses, dielectric losses, losses due to continuous loading of measuring instruments, due to control elements load etc.

The variable losses are current dependent losses and hence they are dependent upon the amount of energy distributed. These losses amount between $2 / 3$ and $3 / 4$ of total technical losses.

Fixed losses remain fixed but variable losses can be reduced by proper choice of distributed generator (DG) when placed in the distribution system. DGs are classified based upon the type of power they can deliver. They are categorized as type 1 to type 4 .

\section{TEST SYSTEM AND METHODOLOGY}

An IEEE 33 bus test distribution system is taken into consideration for the analysis. This is a radial distribution system, with bus 1 as the slack bus. Total loading of the system is 3.7 MW and 2.3 MVAr.The voltage at bus 1 is $12.66 \mathrm{KV}$ which is the base voltage and is taken as 1.0 per unit. The system is studied first in respect of total system losses and the voltage profile of the system. After running the load flow analysis total system losses are found to be $200.1512 \mathrm{~kW}$.

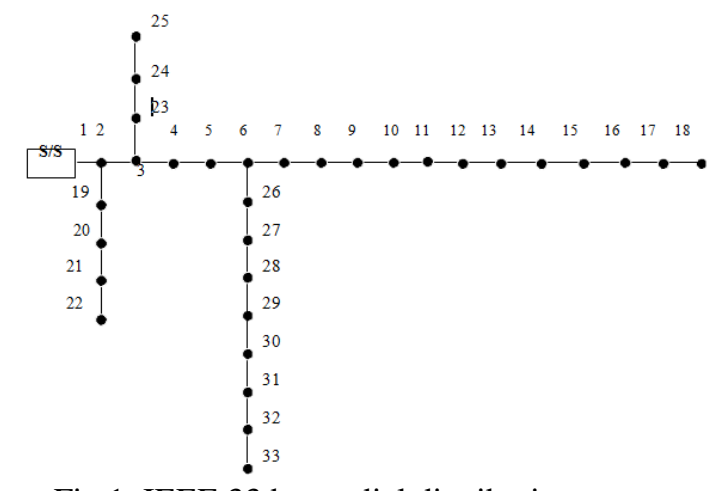

Fig.1. IEEE 33 bus radial distribution system

And voltage profile of the system is as shown below in figure 2:

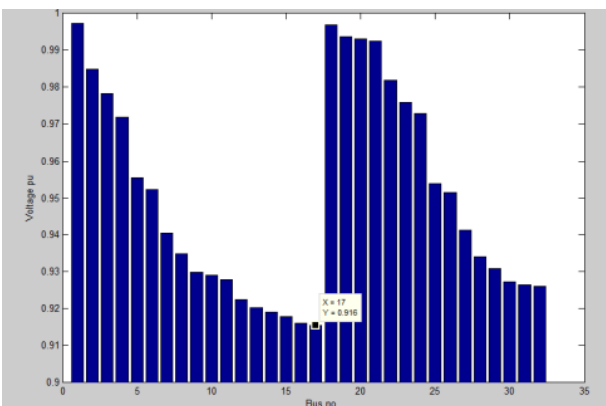

Fig.2. System voltage profile before DG placement

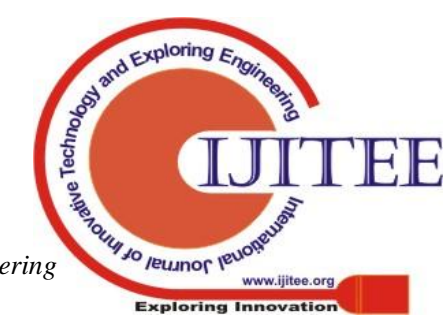


The minimum bus voltage is obtained at bus no. 17 and it is $0.916 \mathrm{pu}$.

\section{A. Methodology: DG Size}

For determination of optimal DG size the paper uses exact loss formula[8] and its solution for loss minimization is obtained by analytical method.Distribution network performance analysis requires repeated load flow analysis of the same. Load flow calculations are basically the line power flow calculations which provide the knowledge of steady state operating state of the system for a particular load level. Knowledge of steady state operating condition of the network with the help of load flow analysis provides continuous monitoring of the system and is helpful in stability studies, planning and optimization of the system. Applications like distribution network optimization require repeated load flows. With the help of load flow analysis various parameters of interest for system analysis, i.e. various node voltages, branch currents, and losses can be determined [9]. The traditional methods of Gauss-Seidel, Newton-Raphson etc. do not suit for load flow analysis of distribution system because of the radial/tee nature of distribution network and distribution system's ill conditioning due to the high $\mathrm{R} / \mathrm{X}$ ratio as compared to the transmission system, which otherwise, follows meshed network structure and has a low $\mathrm{R} / \mathrm{X}$ ratio. The load flow analysis is the backbone of the distribution system optimization [10]. As for analysis purpose, the load flow has to run many a times; it must be robust in nature and must consume minimum time. This work uses a method of load flow that uses topological structure and Kirchhoff's current law for load flow calculations. Initially following three steps are required: determination of equivalent current injection, formation of BIBC matrix, formation of BCBV matrix. BIBC matrix is formed by applying Kirchhoff's current law at various buses or nodes and the BCBV matrix is formed by applying Kirchhoff's voltage law at various buses/nodes. Once BIBC and BCBV matrices are known, bus current injection and bus voltages can be related as [11]

$[\Delta V]=[B C B V][B I B C][I]=[D L F][I]$

The solution to load flow can be determined as follows:

$$
\begin{aligned}
& I_{i}^{k}=I_{i}^{r}\left(V_{i}^{k}\right)+j * I_{i}^{i}\left(V_{i}^{k}\right)=\left(\frac{P_{i}+j * Q_{i}}{V_{i}^{k}}\right) \\
& {\left[\Delta V^{k+1}\right]=[D L F]\left[I^{k}\right]} \\
& {\left[V^{k+1}\right]=\left[V^{0}\right]+\left[\Delta V^{k+1}\right]}
\end{aligned}
$$

The solution to load flow requires two matrices and their multiplication.

A large number of techniques are proposed for optimal location of DG, the analytical technique is one of them [12]. The paper uses analytical technique for determination of optimal DG size and a methodology based upon minimum real power losses in distribution system for optimal site/location determination. For this purpose exact loss formula [10] is used which is given as:

$P_{l}=\sum_{i=1}^{N} \sum_{j=1}^{N}\left[\alpha_{i j}\left(P_{i} P_{j}+Q_{i} Q_{j}\right)+\beta_{i j}\left(Q_{i} P_{j}-P_{i} Q_{j}\right)\right]$

in which

$$
\begin{aligned}
& \alpha_{i j}=\frac{r_{i j}}{V_{i} V_{j}} \cos \left(\delta_{i}-\delta_{j}\right), \\
& \beta_{i j}=\frac{r_{i j}}{V_{i} V_{j}} \sin \left(\delta_{i}-\delta_{j}\right),
\end{aligned}
$$

and

$r_{i j}+j x_{i j}=Z_{i j}$, being $\mathrm{ij}^{\text {th }}$ element of Z-bus matrix [Zbus] also [Zbus $]=\left[\mathrm{Ybus}^{-1}\right.$

$\mathrm{P}_{\mathrm{i}}, \mathrm{P}_{\mathrm{j}}, \mathrm{Q}_{\mathrm{i}}$ and $\mathrm{Q}_{\mathrm{j}}$ are the real and reactive power injected at $\mathrm{i}^{\text {th }}$ bus and the $\mathrm{j}^{\text {th }}$ bus respectively and $\mathrm{N}$ is the total number of buses.

Knowing the power factor of DG, the equation of DG reactive power in terms of $D G$ active power can be written as [13]

$$
\begin{aligned}
& Q_{D G i}=\left[ \pm \tan \left\{\cos ^{-1}\left(P F_{D G}\right)\right\} P_{D G i}\right] \\
& Q_{D G i}=a\left(P_{D G i}\right) \\
& a= \pm \tan \left\{\cos ^{-1}\left(P F_{D G}\right)\right\}
\end{aligned}
$$

If sign of ' $a$ ' is positive DG injects reactive power and if it is positive DG withdraws reactive power.

The sizing at various locations can be determined as

$$
\begin{aligned}
& P_{i}=P_{D G i}-P_{D i} \\
& Q_{i}=Q_{D G i}-Q_{D i}=a P_{D G i}-Q_{D i}
\end{aligned}
$$

Where, $P_{i}$ and $Q_{i}$ are the net values of real and reactive power at $i^{\text {th }}$ bus. $P_{D i}$ and $Q_{D i}$ are the real and reactive load powers at $\mathrm{i}^{\text {th }}$ bus. $\mathrm{P}_{\mathrm{DGi}}$ and $\mathrm{Q}_{\mathrm{DGi}}$ are the real and reactive power supplied by distributed generators at $i_{\text {th }}$ bus [14]

The equations (1) and (3) can be combined to write down the system real power loss as [15]:

$$
\begin{array}{r}
P_{L}=\sum_{i=1}^{N} \sum_{j=1}^{N}\left[\alpha_{i j}\left[\left(P_{D G i}-P_{D i}\right) P_{j}+\left(a P_{D G i}-Q_{D i}\right) Q_{j}\right]+\right. \\
\left.\beta_{i j}\left[\left(P_{D G i}-P_{D i}\right) P_{j}+\left(a P_{D G i}-Q_{D i}\right) Q_{j}\right]\right]
\end{array}
$$

Now if the partial derivative of this equation is taken with respect to the active power injection at bus ' $i$ ' and is equated to zero, the total active power loss of the system would be zero. Solving the partial derivative and rearranging

$$
\frac{\partial P_{L}}{\partial P_{D G i}}=2 \sum_{j=1}^{N}\left[\alpha_{i j}\left(P_{j}+a Q_{j}\right)+\beta_{i j}\left(a P_{j}-Q_{j}\right)\right]=0
$$

The above equation is re-written as

$$
\begin{aligned}
& \alpha_{i i}\left(P_{i}+a Q_{i}\right)+\beta_{i i}\left(a P_{i}-Q_{i}\right)+\sum_{\substack{j=1 \\
j \neq i}}^{N}\left(\alpha_{i j} P_{j}-\beta_{i j} Q_{j}\right) \\
& +a \sum_{\substack{j=1 \\
j \neq i}}^{N}\left(\alpha_{i j} Q_{j}+\beta_{i j} P_{j}\right)=0
\end{aligned}
$$

In this equation, let 


$$
\begin{aligned}
& \sum_{\substack{j=1 \\
j \neq i}}^{N}\left(\alpha_{i j} P_{j}-\beta_{i j} Q_{j}\right)=\mathrm{X}_{\mathrm{i}} \\
& \text { and } \\
& a \sum_{\substack{j=1 \\
j \neq i}}^{N}\left(\alpha_{i j} Q_{j}+\beta_{i j} P_{j}\right)=\mathrm{Y}_{\mathrm{i}}
\end{aligned}
$$

From equation (3), (4), (6) and (7) following equation can be developed as

$$
\alpha_{i i}\left(P_{D G i}-P_{D i}+a^{2} P_{D G i}-a Q_{D i}\right)+\beta_{i i}\left(Q_{D i}-a P_{D i}\right)+X_{i}+a Y_{i}=0
$$

From this equation, the optimal size of DG, at $i^{\text {th }}$ (where ' $i$ ' is varying from 1 to $\mathrm{N}$ ) bus can be determined using following equation:

$$
P_{D G i}=\frac{\alpha_{i i}\left(P_{D i}+a Q_{D i}\right)+\beta_{i i}\left(a P_{D i}-Q_{D i}\right)-X_{i}-a Y_{i}}{a^{2} \alpha_{i i}+\alpha_{i i}}
$$

A complex distribution system, in general, has a few generation sources and a number of buses, lines and many loads. Losses in the system are minimum if each load is locally supplied by a DG and the DG power factor is exactly equal to the load power factor. But it is an unrealistic approach for practical implementation as it will result in a huge investment in DG installation, also the transmission lines would become of no use. Literaturesshow that the optimal DG operating power factor is determined by the fast method and the repeated method. But it is found that the total real power losses are minimum if the power factor of DG is taken as equal to the average power factor of the combined load.

Once the DG power factor is known, optimal size of DG at each bus in the distribution system can be determined for all the four types of distributed generators, in the manner given below:

(a) DG type 1:Type 1 DG like solar photovoltaic (SPV) are capable of supplying only real power to the distribution network [15]. The optimal sizes for these real power sources can be found out by using equation (9) and assuming DG power factor $\mathrm{PF}_{\mathrm{DG}}=1$, with this ' $\mathrm{a}$ ' becomes zero and equation is reduced to [16]

$$
P_{D G i}=P_{D i}-\frac{1}{\alpha_{i i}}\left[\beta_{i i} Q_{D i}+\sum_{\substack{j=1 \\ j \neq i}}\left(\alpha_{i j} P_{j}-\beta_{i j} Q_{j}\right)\right]
$$

(b) DG type 2: Their capacity can be obtained by using the same equation (9) but now the condition is $\mathrm{PF}_{\mathrm{DG}}=0$ so ' $\mathrm{a}$ ' becomes infinite. The condition is justified as type $2 \mathrm{DG}$ is capable of supplying only the reactive power to the distribution system. They may be the synchronous condensers. With this the equation (9) reduces to the following form

$$
Q_{D G i}=Q_{D i}+\frac{1}{\alpha_{i i}}\left[\beta_{i i} P_{D i}-\sum_{\substack{j=1 \\ j \neq i}}\left(\alpha_{i j} Q_{j}+\beta_{i j} P_{j}\right)\right]
$$

(c) DG type 3: Under this category come generation facilities like gas turbines which are based upon synchronous generators. The constant ' $a$ ' is positive for this case and its value lies between zero and one. Optimal size of DG at each bus can be determined by equation (9) and equation (4), for real power and reactive power respectively.

(d) DG type 4: For this type of $\mathrm{DG}$ as well the $\mathrm{PF}_{\mathrm{DG}}$ lies between 0 and 1 , but sign of constant ' $a$ ' is negative. They are the generators which supplies real power to the distribution system but at the same time withdraws reactive power fro the supply. The supply authorities do not encourage such withdrawal of reactive power, so, for the purpose capacitors are connected near the terminals of these DGs. Asynchronous/ Induction generators comes under this category of DG type. The optimal capacity can be determined using the equations (9) and (4) respectively, for real and reactive power, while taking negative sign for constant ' $a$ ' [16].

\section{B. Methodology: DG Placement}

Once optimal sizes of DG are known, the next step is the determination of optimal placement site for the optimally sized DG. For this a procedure employing determination of total real power losses with optimally sized DG placed at each bus, one at a time, is followed. The steps for the same can be summarized as follows [15],[16]:

$1^{\text {st }}$ step: Running the load flow for base case.

$2^{\text {nd }}$ step: Determination of total loss using equation (1).

$3^{\text {rd }}$ step: Determination of DG power factor by calculating average load power factor.

$4^{\text {th }}$ step: Finding optimal DG size at each bus using equations (9) and (4).

$5^{\text {th }}$ step: Placement of optimal DG sizes at each bus for total real power loss with DG at each bus one at a time.

$6^{\text {th }}$ step: Locating the bus at which placement of optimal DG causes total system losses to become minimum.

$7^{\text {th }}$ step: Running load flow after placement of optimal sized DG at optimal bus location. Observe the bus voltage profile as well.

\section{Methodology: Economics of Optimal DG Placement}

To obtain economical benefit of DG placement, benefit of reduced energy loss cost and benefit of cost due to reduced supply drawn from substation is compared to the installation and maintenance cost of distributed generator.

Cost of Energy Loss: The energy lost in a certain time can be determined as:

$L_{e}=\sum_{i=1}^{n} L e i$

Where,

$L e i=I_{i} \times I_{i} \times R \times T$

Knowing $\mathrm{L}_{\mathrm{e}}$, the cost of lost energy can be determined as 
$C E L=\operatorname{Re} \times L_{e}$

$R_{e}$ is rate of energy and $L_{e}$ is the lost energy.

DG Cost : The total DG cost comprises of two parts which are the fixed installation cost and the variable cost .

$\mathrm{CDG}=\mathrm{C}_{\mathrm{cv}} * \mathrm{Q}_{\mathrm{ck}}$

$\mathrm{C}_{\mathrm{cv}} \& \mathrm{Q}_{\mathrm{ck}}$ are rate of DG per MW/MVA and rating of DG at $\mathrm{k}$-th bus respectively.

The objective function for cost minimization can now be framed as:

$\mathrm{F}=\mathrm{CEL}+\mathrm{C}_{\mathrm{cv}} * \mathrm{Q}_{\mathrm{ck}}$; where $\mathrm{F}$ is the cost function for minimization.

Second part of equation is dependent upon the DG technology used. Nothing can be done for DG installation cost reduction, but first par is representing the cost of energy lost and it can be minimized if DGs are placed optimally in respect of loss minimization.

For the foregoing analysis of given system, the system is studied with the peak power demand. For the purpose of economics of loss calculations the average loading per day is considered which is approximately $60 \%$ of the peak load demand. The power lost is dependent upon the current squared, so the reduction of power level from peak value to average value causes the losses to get reduced to $36 \%$. Further it is assumed that type 1 to type 4 DG are supplying power for eight hours in a day. For rest of the time, i.e. for 16 hours all thepower is withdrawn from substation.

\section{RESULT}

Optimal size and location for four type of DGs are determined using analytical method. Type one DG which injects only real power may be a solar PV system, type two that basically supplies only the reactive power may be a synchronous compensator or may be the static capacitors [17],[18],[19]. Type three DG which are capable of supplying active as well as reactive powers are basically the synchronous generator based DGs and may involve gas turbines. Type four DGs are the one which supplies active power but withdraws reactive power from supply. Induction generators used for wind power generation fall in this category. For system study a program is written in MATLAB environment.

\section{A. Optimal Placement of DG}

From table I it can be seen that minimum losses are obtained if optimal sized type 1 DG is placed at bus no.7, so from loss minimization point of view, bus no. 7 becomes the optimal placement site for type $1 \mathrm{DG}$.

After placing this DG, the system voltage profile is also observed and it is found that this placement causes an improvement in voltage profile as well.

Table I: Type 1 DG Optimal Sizes and corresponding losses

\begin{tabular}{|c|c|c|c|}
\hline S. NO. & $\mathbf{P}_{\mathrm{DG}}(\mathbf{M W})$ & $\mathbf{P}_{\mathrm{i}}(\mathbf{M W})$ & $\mathbf{P}_{\text {Loss }}(\mathrm{KW})$ \\
\hline 2 & 3.3334 & 3.2334 & 191.1538 \\
\hline 3 & 3.5909 & 3.5009 & 152.8956 \\
\hline 4 & 3.3866 & 3.2666 & 141.4717 \\
\hline 5 & 3.0922 & 3.0322 & 130.1902 \\
\hline 6 & 2.9315 & 2.8715 & 108.1198 \\
\hline 7 & 2.6646 & 2.4646 & 108.0375 \\
\hline 8 & 2.5925 & 2.3925 & 129.2028 \\
\hline 9 & 1.9312 & 1.8712 & 120.5075 \\
\hline 10 & 1.7191 & 1.6591 & 122.0745 \\
\hline 11 & 1.5593 & 1.5143 & 120.029 \\
\hline 12 & 1.534 & 1.474 & 121.4819 \\
\hline 13 & 1.493 & 1.433 & 129.0271 \\
\hline 14 & 1.3275 & 1.2075 & 129.0721 \\
\hline 15 & 1.2736 & 1.2136 & 130.1355 \\
\hline 16 & 1.2176 & 1.1576 & 133.6032 \\
\hline 17 & 1.1525 & 1.0925 & 140.5815 \\
\hline 18 & 1.0488 & 0.9588 & 142.0009 \\
\hline 19 & 0.9057 & 0.8157 & 196.637 \\
\hline 20 & 2.9578 & 2.8678 & 260.224 \\
\hline 21 & 1.2529 & 1.1629 & 206.6889 \\
\hline 22 & 1.0956 & 1.0056 & 207.8386 \\
\hline 23 & 0.8996 & 0.8096 & 176.7704 \\
\hline 24 & 2.7155 & 2.2955 & 177.0284 \\
\hline 25 & 1.9324 & 1.5124 & 177.1937 \\
\hline 26 & 1.4708 & 1.4108 & 121.9327 \\
\hline 27 & 2.5336 & 2.4736 & 111.6375 \\
\hline 28 & 2.4048 & 2.3448 & 122.9002 \\
\hline 29 & 2.0078 & 1.8878 & 121.6295 \\
\hline 30 & 1.793 & 1.593 & 121.6852 \\
\hline 31 & 1.6772 & 1.5272 & 129.3372 \\
\hline 32 & 1.471 & 1.261 & 128.7765 \\
\hline 33 & 1.408 & 1.348 & 132.4148 \\
\hline
\end{tabular}

Fig.3. Voltage profile after type 1 DG placement at bus no.

Now considering type 2 DG placement, the problem with type 2 is they cannot supply active power they only supply the reactive power. Reactive power supply improves system's voltage profile and reduces the magnitude of current drawn from sub-station as it becomes a local supplier of reactive power.

The table of optimum size of Q-generator at different busses in system is given as table 2. It also contains the best location for the same by considering total minimum real power losses obtained by placing optimum DG sizes one at a time at respective buses. The best location is one that provides total minimum loss.

The improved voltage profile of the system with optimal DG placement, which is at bus no. 30 , is shown in figure $4 \mathrm{~b}$. As seen the minimum voltage got improved to $0.928 \mathrm{pu}$ at bus 17 counting from bus 2 (bus 1 being the substation

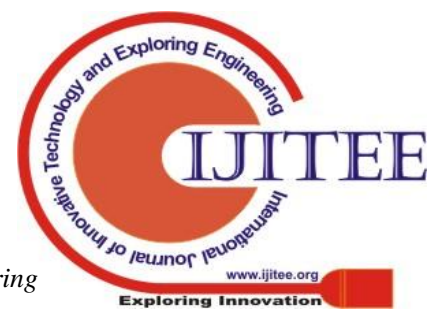


bus), so it is actually the bus no. 18 of the 33 bus system.

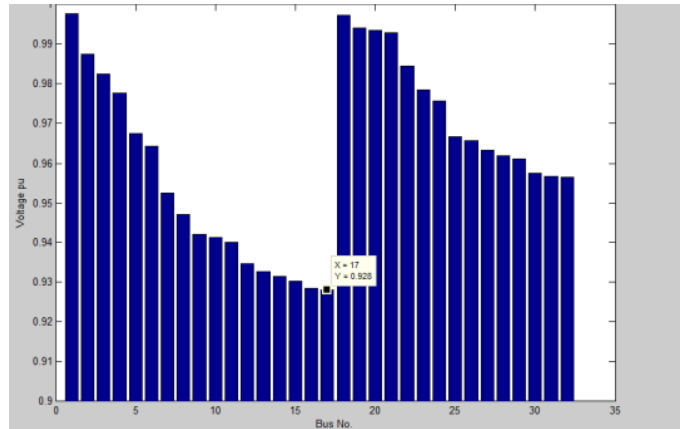

Fig.4. Voltage profile after optimum type 2 DG placement at bus no. 30

Type 3 DGs are those which can supply real power as well as reactive power. Optimal sizes and the losses with them are given in table 3 . The optimum site is found to be the bus no. 6 of the system as it is providing minimum real power losses in the system. After placing optimum sized DG at bus no. 6 the obtained system voltage profile is given in following fig.5

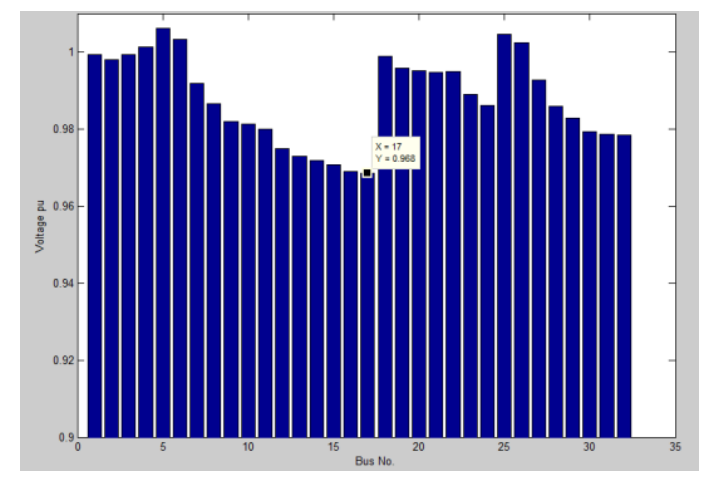

Fig.5. Voltage profile after optimum type 3 DG placement at bus no. 6
Table II: Type 2 DG Optimal Sizes and corresponding losses

\begin{tabular}{|c|c|c|c|}
\hline S. NO. & $\mathbf{Q}_{\mathrm{DG}}(\mathbf{M V A r})$ & $\mathbf{Q}_{\mathrm{i}}(\mathbf{M V A r})$ & $\mathbf{P}_{\text {Loss }}(\mathrm{KW})$ \\
\hline 2 & 2.0472 & 1.9872 & 196.6892 \\
\hline 3 & 2.2035 & 2.1635 & 180.7433 \\
\hline 4 & 2.1048 & 2.0248 & 174.0828 \\
\hline 5 & 1.9612 & 1.9312 & 167.7434 \\
\hline 6 & 1.8937 & 1.8737 & 154.1925 \\
\hline 7 & 1.773 & 1.673 & 155.303 \\
\hline 8 & 1.7167 & 1.6167 & 172.1124 \\
\hline 9 & 1.2223 & 1.2023 & 168.8537 \\
\hline 10 & 1.068 & 1.048 & 170.646 \\
\hline 11 & 0.9549 & 0.9249 & 169.7585 \\
\hline 12 & 0.9368 & 0.9018 & 170.7323 \\
\hline 13 & 0.9088 & 0.8738 & 175.1796 \\
\hline 14 & 0.7952 & 0.7152 & 174.5477 \\
\hline 15 & 0.7584 & 0.7484 & 175.9225 \\
\hline 16 & 0.7218 & 0.7018 & 177.5924 \\
\hline 17 & 0.6812 & 0.6612 & 180.4953 \\
\hline 18 & 0.6171 & 0.5771 & 180.9713 \\
\hline 19 & 0.5242 & 0.4842 & 198.9234 \\
\hline 20 & 1.8095 & 1.7695 & 224.8321 \\
\hline 21 & 0.7445 & 0.7045 & 203.1403 \\
\hline 22 & 0.6488 & 0.6088 & 203.905 \\
\hline 23 & 0.5307 & 0.4807 & 191.6169 \\
\hline 24 & 1.6555 & 1.4555 & 193.6902 \\
\hline 25 & 1.1552 & 0.9552 & 193.6079 \\
\hline 26 & 0.8735 & 0.8485 & 164.6318 \\
\hline 27 & 1.7025 & 1.6775 & 152.8438 \\
\hline 28 & 1.6461 & 1.6261 & 150.2158 \\
\hline 29 & 1.4649 & 1.3949 & 146.3259 \\
\hline 30 & 1.3633 & 0.7633 & 144.4078 \\
\hline 31 & 1.2664 & 1.1964 & 151.3425 \\
\hline 32 & 1.1014 & 1.0014 & 152.1337 \\
\hline 33 & 1.0542 & 1.0142 & 154.8909 \\
\hline
\end{tabular}


Table III: Type 3 DG Optimal sizes and corresponding losses

\begin{tabular}{|c|c|c|c|c|}
\hline $\begin{array}{c}\text { S. } \\
\text { NO. }\end{array}$ & $\begin{array}{c}\mathbf{P}_{\text {DG }} \\
\text { (MW) }\end{array}$ & $\begin{array}{c}\mathbf{Q}_{\text {DG }} \\
\text { (MVAr) }\end{array}$ & $\begin{array}{c}\mathbf{S} \\
\text { (MVA) }\end{array}$ & $\begin{array}{c}\mathbf{P}_{\text {LOss }} \\
(\mathbf{K W})\end{array}$ \\
\hline 2 & 3.3334 & 2.0667 & 3.9216 & 187.7045 \\
\hline 3 & 3.5909 & 2.2264 & 4.2246 & 134.3382 \\
\hline 4 & 3.3866 & 2.0997 & 3.9842 & 116.9103 \\
\hline 5 & 3.0922 & 1.9172 & 3.6379 & 100.0601 \\
\hline $\mathbf{6}$ & $\mathbf{2 . 9 3 1 5}$ & $\mathbf{1 . 8 1 7 5}$ & 3.4488 & $\mathbf{6 7 . 0 9 0 1}$ \\
\hline 7 & 2.6646 & 1.652 & 3.1348 & 67.546 \\
\hline 8 & 2.5925 & 1.6073 & 3.05 & 98.5458 \\
\hline 9 & 1.9312 & 1.1974 & 2.272 & 90.1299 \\
\hline 10 & 1.7191 & 1.0658 & 2.0224 & 93.4506 \\
\hline 11 & 1.5593 & 0.9667 & 1.8344 & 91.2797 \\
\hline 12 & 1.534 & 0.9511 & 1.8047 & 93.5017 \\
\hline 13 & 1.493 & 0.9256 & 1.7564 & 103.9067 \\
\hline 14 & 1.3275 & 0.8231 & 1.5618 & 102.5171 \\
\hline 15 & 1.2736 & 0.7896 & 1.4984 & 106.0017 \\
\hline 16 & 1.2176 & 0.7549 & 1.4325 & 110.6294 \\
\hline 17 & 1.1525 & 0.7146 & 1.3559 & 118.9657 \\
\hline 18 & 1.0488 & 0.6503 & 1.2339 & 121.0881 \\
\hline 19 & 0.9057 & 0.5615 & 1.0655 & 195.3554 \\
\hline 20 & 2.9578 & 1.8338 & 3.4797 & 281.9182 \\
\hline 21 & 1.2529 & 0.7768 & 1.474 & 209.7521 \\
\hline 22 & 1.0956 & 0.6793 & 1.2889 & 211.1912 \\
\hline 23 & 0.8996 & 0.5577 & 1.0583 & 168.0226 \\
\hline 24 & 2.7155 & 1.6836 & 3.1947 & 170.0453 \\
\hline 25 & 1.9324 & 1.1981 & 2.2734 & 170.3551 \\
\hline 26 & 1.4708 & 0.9119 & 1.7304 & 87.8553 \\
\hline 27 & 2.5336 & 1.5708 & 2.9807 & 68.8874 \\
\hline 28 & 2.4048 & 1.491 & 2.8292 & 75.9692 \\
\hline 29 & 2.0078 & 1.2449 & 2.3622 & 71.7697 \\
\hline 30 & 1.793 & 1.1117 & 2.1094 & 70.9852 \\
\hline 31 & 1.6772 & 1.0399 & 1.9732 & 82.1802 \\
\hline 32 & 1.471 & 0.912 & 1.7306 & 83.8927 \\
\hline 33 & 1.408 & 0.873 & 1.6565 & 88.9162 \\
\hline
\end{tabular}

Type 4 DGs are basically induction generators connected to the supply system. They supply real power to the system but at the same time they withdraw reactive power form supply. The optimal DG sizes are given in the following table and the corresponding losses are also mentioned.

The improvement in system voltage profile after placement of DG 4 at bus number 25 results 0.926 pu voltage at bus 17 . This type of DG installation increases the substation capacity which is not permitted. So this placement is not possible without capacitor placement to support DG4 reactive power requirement
Table IV: Type 4 DG Optimal sizes and corresponding losses

\begin{tabular}{|c|c|c|c|c|}
\hline $\begin{array}{l}\text { S. } \\
\text { NO. }\end{array}$ & $\begin{array}{l}\mathbf{P}_{\mathrm{DG}} \\
(\mathrm{MW})\end{array}$ & $\begin{array}{l}\mathbf{Q}_{\mathrm{DG}} \\
\text { (MVAr) }\end{array}$ & S (MVA) & $\begin{array}{l}\mathbf{P}_{\text {Loss }} \\
\text { (KW) }\end{array}$ \\
\hline 1 & 3.3334 & -2.0667 & 3.9216 & 199.3776 \\
\hline 2 & 3.5909 & -2.2264 & 4.2246 & 207.3288 \\
\hline 3 & 3.3866 & -2.0997 & 3.9842 & 218.4699 \\
\hline 4 & 3.0922 & -1.9172 & 3.6379 & 222.2997 \\
\hline 5 & 2.9315 & -1.8175 & 3.4488 & 242.5286 \\
\hline 6 & 2.6646 & -1.652 & 3.1348 & 234.4628 \\
\hline 7 & 2.5925 & -1.6073 & 3.05 & 300.6461 \\
\hline 8 & 1.9312 & -1.1974 & 2.272 & 251.2425 \\
\hline 9 & 1.7191 & -1.0658 & 2.0224 & 246.925 \\
\hline 10 & 1.5593 & -0.9667 & 1.8344 & 231.1012 \\
\hline 11 & 1.534 & -0.9511 & 1.8047 & 233.795 \\
\hline 12 & 1.493 & -0.9256 & 1.7564 & 251.9742 \\
\hline 13 & 1.3275 & -0.8231 & 1.5618 & 236.5905 \\
\hline 14 & 1.2736 & -0.7896 & 1.4984 & 237.0257 \\
\hline 15 & 1.2176 & -0.7549 & 1.4325 & 238.5434 \\
\hline 16 & 1.1525 & -0.7146 & 1.3559 & 236.1743 \\
\hline 17 & 1.0488 & -0.6503 & 1.2339 & 237.4895 \\
\hline 18 & 0.9057 & -0.5615 & 1.0655 & 198.9023 \\
\hline 19 & 2.9578 & -1.8338 & 3.4797 & 308.0637 \\
\hline 20 & 1.2529 & -0.7768 & 1.474 & 219.3851 \\
\hline 21 & 1.0956 & -0.6793 & 1.2889 & 220.4645 \\
\hline 22 & 0.8996 & -0.5577 & 1.0583 & 189.6181 \\
\hline 23 & 2.7155 & -1.6836 & 3.1947 & 252.1943 \\
\hline 24 & 1.9324 & -1.1981 & 2.2734 & 235.0709 \\
\hline 25 & 1.4708 & -0.9119 & 1.7304 & 182.8092 \\
\hline 26 & 2.5336 & -1.5708 & 2.9807 & 241.1323 \\
\hline 27 & 2.4048 & -1.491 & 2.8292 & 282.4202 \\
\hline 28 & 2.0078 & -1.2449 & 2.3622 & 270.2093 \\
\hline 29 & 1.793 & -1.1117 & 2.1094 & 261.1407 \\
\hline 30 & 1.6772 & -1.0399 & 1.9732 & 269.9803 \\
\hline 31 & 1.471 & -0.912 & 1.7306 & 250.2721 \\
\hline 32 & 1.408 & -0.873 & 1.6565 & 250.4048 \\
\hline
\end{tabular}

\section{B. Economic analysis of Optimal DG Placement}

For the economic analysis of the system, the system is studied with the peak power demand. For the purpose of economics of loss calculations the average loading per day is considered which approximately $60 \%$ of the peak load demand. The power lost is dependent upon the current squared, so the reduction of power level from peak value to average value causes the losses to get reduced to $36 \%$. Further it is assumed that DGs are supplying power for a duration of 8 hours in a day and for rest 16 hours the power is being supplied by the substation.

The loss cost with four DG types is tabulated in table V: 
Table V: Loss cost comparison of system

\begin{tabular}{|c|c|c|c|c|}
\hline Observation & Loss (kW) & $\begin{array}{l}\mathrm{V}_{\min } \\
\text { @ } 17^{*}\end{array}$ & $\begin{array}{l}\text { Loss Cost (in } \\
\text { lacs/annum) }\end{array}$ & $\begin{array}{l}\text { Saving (in lacs } \\
\text { per annum) }\end{array}$ \\
\hline Base Case & $200.15 \mathrm{~kW}$ & 0.916 & Rs. 37.87/- & - \\
\hline Type 1 & 108.0375 & 0.952 & Rs.32.06/- & Rs. 5.81/- \\
\hline Type 2 & 144.4078 & 0.928 & Rs.34.36/- & Rs. 3.51/- \\
\hline Type 3 & 67.0901 & 0.968 & Rs.29.48/- & Rs. 8.39/- \\
\hline Type4 & 182.8092 & 0.926 & Rs. 36.78/- & Rs.1.09/- \\
\hline
\end{tabular}

* Bus 17 as counted from bus 2 . It is bus no. 18 of the 33 bus system.

\section{SUMMARY}

\section{A. Optimal Placement of DG for Loss Minimization}

Foregoing analysis of optimal DG placement is summarized in following table:

Table VI: Optimum size and site

\begin{tabular}{|c|c|c|c|c|}
\hline \multirow[t]{2}{*}{ DG type } & \multicolumn{3}{|c|}{ DG Capacity } & \multirow{2}{*}{$\begin{array}{l}\text { DG } \\
\text { Location } \\
\text { (bus no.) }\end{array}$} \\
\hline & $\mathbf{P}(\mathbf{M W})$ & Q(MVAr) & S(MVA) & \\
\hline Type 1 & 2.6646 & - & - & 7 \\
\hline Type 2 & - & 1.3633 & 1.3633 & 30 \\
\hline Type 3 & 2.9315 & 1.8175 & 3.4488 & 6 \\
\hline Type 4 & 1.4708 & -0.9119 & 1.7304 & 25 \\
\hline
\end{tabular}

\section{B. Economics of DG Placement}

Benefit obtained in cost reduction due to system loss minimization can be summarized as given in following table.

Table VII: Loss cost reduction benefit

\begin{tabular}{|c|c|}
\hline DG Type & Benefit (in lacs per annum) \\
\hline Type 1 & Rs. 5.81/- \\
\hline Type 2 & Rs. 3.51/- \\
\hline Type 3 & Rs. 8.39/- \\
\hline Type 4 & Rs. 1.09/- \\
\hline
\end{tabular}

\section{CONCLUSION}

The paper is written for the purpose of comparing the economic feasibility four type of distributed generators placement in primary distribution network. This is done by optimizing loss cost of DG with the help of optimum sized DGs placed at optimal nodes in the radial distribution system. Analytical method using exact loss formula is used for determination of optimal size and a methodology is then employed for the purpose of determining optimal location. The best sites so obtained are not always feasible for DG placement because of many constraints, but as the losses increase with a variation in optimal size and site, so this factor must be taken into account. Load flow analysis is done for determination of various bus voltages, branch currents and active power loss in the system. Results of all optimum placement for all four type of DGs are shown and it is found that Type 3 DG placement is the best option economically as well as technically in terms of voltage profile betterment. Economics of DG placement for each case is given by respective table. The benefit of DG placement is determined in terms of saving in real power losses. Monetary benefit can also be attained by relieving some capacity of the substation and hence by proper design the substation size can be reduced. The economic analysis can further be extended by incorporating DG fixed and variable costs and for determination of payback period.

CERC (central Electricity Regulatory Commission) website is referred to get the costs for DG cost determination and the costs are approximated [23].

\section{REFERENCES}

[1] Duong Quoc Hung and Nadarajah Mithulananthan,. "Multiple Distributed Generator Placement in Primary Distribution Networks for Loss Reduction," IEEE Transactions on Industrial Electronics, vol.60, no. 3, April 2013

[2] Thomas Ackermann, Go“ran Andersson, Lennart Soder, "Distributed generation: a definition" Electric Power Systems Research, vol.57, pp 195-204, 2001.

[3] Pabla A S, Electric Power Distribution, Tata Mc-Graw Hill Education, 2004.

[4] R. Sanjay; T.Jayabarathi; T. Raghunathani; V. Ramesh; Nadarajah Mithulananthan, "Optimal Allocation of Distributed Generation Using Hybrid Grey Wolf Optimizer", IEEE Access, date of publication July 21,2017

[5] Mario ŠIPOŠ, Zvonimir KLAIĆ, Krešimir FEKETE, Marinko STOJKOV,"Review of Non-Traditional Optimization Methods for Allocation of Distributed Generation and Energy Storage in Distribution System” Technical Gazette 25, 1(2018), 294-301

[6] J. A. Pecas Lopes, N. Hatziargyriou, J. Mutale, P. Djapic, N.Jenkins, “ Integrating Distributed Generation into Electric Power Systems: A Review of Drivers, Challenges and Opportunities" Electrir Power System Research, Elsevier Science Ltd. Vol 77, pp 1189-1203, 2007

[7] R. Srinivasa Rao ; K. Ravindra ; K. Satish ; S. V. L. Narasimham, "Power Loss Minimization in Distribution System Using Network Reconfiguration in the Presence of Distributed Generation" IEEE Transactions on Power Systems, Volume 28, Issue 1, pp 317 - 325, Feb. 2013

[8] H. Hedayati, S. A. Nabaviniaki, and A. Akbarimajd, "A Method for Placement of DG Units in Distribution Networks," IEEE Transactions on Power Delivery, vol. 23, pp. 1620-1628, 2008.

[9] S. Ghosh and D. Das, "Method for load-flow solution of radial distribution networks", IEE Proceedings on Generation, Transmission \& Distribution, vol. 146, no. 6, pp. 641-648, 1999

[10] J. H. Teng, "A Network-Topology-based Three-Phase Load Flow for Distribution systems", Proceeding National Science Council, Republic of China, vol. 24, no. 4, pp. 259-264, 2000.

[11] J. H. Teng, "A Direct Approach for Distribution System Load Flow Solutions", IEEE Transactions on Power Delivery, vol. 18, no. 3, pp. 882-887, 2003.

[12] P. Sobha Rani, Dr. A Lakshmi Devi, "Optimal Sizing of DG Units Using Exact Loss Formula at Optimal Power factor" International Journal of Engineering Science and Technology, Vol.4 No.09, September 2012.

[13] Amir Ameli, Shahab Bahrami, Farid Khazaeli, Mahmood-Reza Haghifam, "A Multiobjective Particle Swarm Optimization for Sizing and Placement of DGs from DG Owner's and Distribution Company's Viewpoint" IEEE Transactions on Power Delivery, Volume 29, Issue 4, pp 1831 - 1840, Aug. 2014

[14] Mukul Dixit, Prasanta Kundu, Hitesh R. Jariwala "Optimal Placement and Sizing of DG in Distribution system using artificial Bee Colony Algorithm" 2016 IEEE 6th International Conference on Power Systems (ICPS), 4-6 March 2016

[15] N. Acharya, P. Mahat, and N. Mithulananthan, "An analytical approach for DG allocation in primary distribution network," International Journal of Electrical Power \& Energy Systems, vol. 28, pp. 669-678, 2006.

[16] Hung D.Q., Mithulananthan N. and Bansal R.C., "Analytical Expressions for DG Allocation in Primary Distribution Networks," IEEE Transactions on Energy Conversion, vol. 25, no. 3, pp 814-820, 2010

[17] W. Caisheng and M. H. Nehrir, "Analytical approaches for optimal placement of distributed generation sources in power systems," IEEE Transactions on Power Systems, vol. 19, pp. 2068-2076, 2004 
[18] Pavlos S. Georgilakis; Nikos D. Hatziargyriou "Optimal Distributed Generation Placement in Primary Distribution Networks: Models, Methods, and Future Research," IEEE Transactions on Power Systems, Volume: 28, Issue: 3, pp 3420 - 3428, Aug. 2013

[19] Lucian Ioan Dulau, Mihail Abrudean, Dorin Bica, “ Optimal Power Flow Analysis of a Distributed Generation System"Procedia Technology, vol.19, pp $673-680,2015$.

[20] Thomas E Hoff, Howard J Wenger, Brian K Farmer, “ Distributed Generation: An Alternative to Electric Utility Investments in System capacity” Energy Policy, Elsevier Science Ltd.,Vol.24. No. 2. Pp.137-147,1996.

[21] P. Dondi, D. Bayoumi, C. Haederli, D. Julian, and M. Suter, 2002. "Network integration of distributed power generation",Journal of PowerSourcesVol. 106, Issues 1-2, Pages 1-9, April 2002)

[22] Anastasia S. Safigianni, George N. Koutroumpezis, Vassilis C. Poulios, "Mixed distributed generation technologies in a medium voltage network" Electric Power Systems Research Volume 96, pp75-80,March 2013.

[23] https://www.mnre.gov.in

\section{AUTHORS PROFILE}

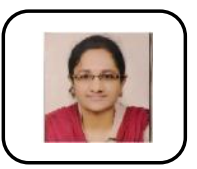

Vani Bhargava is assistant professor Electrical and Electronics Engineering Department, AKG Engineering College , Ghaziabad. She received her BM and ME degree from MITS Gwalior/Jiwaji University and SATIVidisha/RGPV Bhopal respectively. She is currently pursuing Phd from Amity University, Uttar Pradesh, Noida, India.

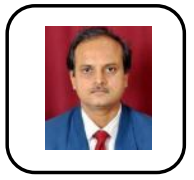

S.K. Sinha is professor, Electrical and Electronics Engineering Department. Amity University, Uttar Pradesh, Noida, India. He received his B.Sc Engineering (Electrical) from M.I.T Muzzaffarpur, Bihar, M.Tech from RIT Jamshedpur (Now NIT Jamshedpur) and Ph.D. from IIT Roorkee with specialization in Power System. He has 23 years of teaching, research and industrial experience.

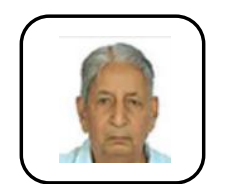

M P Dave passed his B.Sc. \& B.Sc. (Engg.) degrees from Vikram University, Ujjain in the year 1959 and 1963 respectively and completed his M.E. at I.I.Sc. Bangalore in 1965, Ph.D. from Roorkee University in 1969 and Dr-Ing from Ruhr University, Bochum (West Germany) in 1972.He has more than 60 publications mostly in USA and UK and one each in West Germany, Italy and Holland and has guided seven Ph.D. and several M.E. dissertations and projects. He became Fellow of the Institution of Engineers, India in 1988 and chose to become Senior Member of IEEE in 2003. He is having more that 50 years teaching and research experience.Presently he is visiting professor at Shiv Nadar University, Greater Noida, India. 